\title{
REQUIREMENTS FOR HEALTHY DEVELOPMENT OF ADOLESCENT YOUTH
}

\section{Gisela Konopka}

With kind permission from Libra Publishers, Inc.: Adolescence, Requirements for Healthy Development of Adolescent Youth, Vol. 8(31), Fall 1973, pp. 1-26, Konopka, G., (O) Libra Publishing, Inc.

\section{INTRODUCTION}

In the spring of 1973 the Office of Child Development of the Department of Health Education and Welfare asked Gisela Konopka and the Center for Youth Development and Research, University of Minnesota to develop a statement on their concept of normal adolescence and impediments to healthy development. The statement was viewed as a possible base for national policy.

The following is the statement developed in a most interesting process: Gisela Konopka presented her ideas derived from many years of study and experience to the Center staff in three 2-hour sessions. Each point was then discussed by this able staff, consisting of people of various backgrounds, disciplines, and ages. The presentations and discussions were taped and summarized by the editor. Dr. Konopka then reviewed the text with the assistance of Dr. Normal Sprinthall. Editing was done by Lillian Jensen.

The Office of Child Development (HEW) graciously permitted the publication of this document.

\section{PURVIEW OF THIS STATEMENT}

We are talking about adolescent youth in the cultural context of the United States of America in the 1970's. Our objectives are:

- to present a positive developmental model of adolescence by describing what we regard as the key concepts and qualifies of adolescence;

- to set forth some of the conditions for healthy development of adolescent youth; and

- to discuss specific obstacles to such development.

Within this framework we offer a few recommendations concerning programs and research that could facilitate healthy development of adolescent youth.

It should be noted at the outset that whatever is said in this statement (1) never applies totally to one individual because individuals differ; (2) never applies totally to a group or subgroup because ours is a pluralistic culture embodying an infinite variety of subcultures and subgroups; (3) is distinctly intended to be fluid because ours is a culture in transition. 


\section{ADOLESCENCE DEFINED}

Adolescence is defined here as that span of a young person's life between the obvious onset of puberty and the completion of bone growth. We chose a biological definition; others frequently are used. In the cultural context, the age set by a given society for the rites of transition to adulthood could be perceived as marking the end of adolescence. In the United States of the 1970's that age, for the most part, is set at 18. In general, we apply no rigid age limits. We think of the period of 12 to 15 years as early adolescence and 15 to 18 years as middle adolescence. The period of 18 to 22 years might possibly be considered late adolescence. This statement is directed predominantly to early and middle adolescence.

Two other definitions of adolescence should be mentioned."Sociologically, adolescence is the transition period from dependent childhood to self-sufficient adulthood. Psychologically, it is a'marginal situation' in which new adjustment have to be made, namely those that distinguish child behavior from adult behavior in a given society."(1) We do not adhere to either of the two.

Our view of adolescence is eclectic, psychosocial, and goes beyond current existing theories. Central to our concept is this: We do not see adolescence exclusively as a stage that human beings pass through, but rather as a segment of continuing human development. We reject the common conception that adolescence is solely preparation for adulthood, except in the sense that everything in life can be considered to be preparation for what follows. We believe adolescents are persons with specific qualities and characteristics who have a participatory and responsible role to play, tasks to perform, skills to develop at that particular time of life. The degree or extent to which an adolescent experiences such responsible participation will determine and maximize his human development.

\section{CULTURAL CONTEXT}

Since we are talking about adolescent youth in the cultural context of the United States, it seems important to set out a few specific attributes of that culture which we consider particularly relevant to this statement. The list obviously is not intended to be exhaustive.

\section{Pluralism}

Perhaps the word that best characterizes the United States is"variety."Its people fit no common mold. They reflect a broad mix of racial, national, religious, cultural, and socio-economic backgrounds. Their life styles and interests are diverse. They hold various views on what constitutes the "good life."

\section{Acceptance of Difference}

Since ours is a heterogeneous society we must be accepting of difference, or at least work toward that goal. We embrace egalitarianism as an ideal. We reject all forms of discrimination, again ideally. The general development of an increasing 
capacity on the part of each person to respect others and to be respected is seen as a necessary trend.

\section{Participatory Democracy}

Inherent in the representative democratic form of government under which we live is the responsibility of citizens to participate. Every citizen possesses limited political power. Organized groups have greater power. To make democracy work, citizens should be reasonably well informed and be persons of good will-that is, concerned with the common good as well as with the individual, and acting on their concern. Those are not qualities people are born with; they are developed as part of the socialization process.

\section{Human Rights}

Ideologically, ours is an open, free society based on the proposition that the purpose of government is to advance and protect basic human rights. Those rights are presumed to be inalienable - that is, natural, irrevocable, and nontransferable. Society is obligated to create the conditions under which human rights can be secure. Among those that we believe lie closest to the healthy development of youth are:

- the right of the individual to be himself, to think his own thoughts and to speak them, consistent with the rights of others;

- the right to grow and to develop his abilities to their full potential;

- the right to air his grievances and to seek redress;

- the right to make mistakes without unreasonable punishment;

- the right to justice.

What course society will take in the 1970's with respect to supporting the basic rights of individuals and groups remains to be seen. We assume the direction will be positive.

\section{Human Responsibilities}

The enjoyment of rights carries with it the obligation to take responsibility. In our society, concern for one another with alertness toward handicap-producing circumstances is a basic human responsibility. Informed decision making is also a basic responsibility, since roles and opinions are not authoritatively prescribed.

\section{Change}

Attitudes toward change come in all colors of the rainbow. Some people embrace any change simply for the sake of change. Others fight it persistently. Technological change or change in the material sense seems to be generally more acceptable than change in terms of social values, beliefs, morals, ethics, and life styles. 
We assume change in all social domains will continue to be an important element in our culture, though at times its direction may be pendular. Significant changes in the world of work can be anticipated. Institutional change will perhaps continue to be gradual, incremental, and disjointed.

\section{Competition and Upward Mobility}

Emphasis on job advancement and increasing earnings seems to be a durable aspect of our culture. Young men and women entering the labor force may have even higher economic and social expectations than those of a generation ago; they may also be more militant in seeking middle class income and status.(2) The 1971 White House Conference on Youth report, on the other hand, said college age youth give top priority to finding work that addresses critical social problems rather than to jobs that offer the most money and security.

The key consideration here is the social structural availability of choices.

\section{Economy}

Trends to note are (1) the widening gap between the economically well off and the poor-that is, the maldistribution of income and material goods; (2) the increasing concentration of economic power and the growing powerlessness to influence the economy's direction through the economic system; (3) the accumulating evidence that impact on or participation in economic growth, development, and consequences is achieved increasingly by political means.

\section{Urbanization}

Ours is predominantly a complex, organization prone, urban society. Formally organized groups and voluntary associations, focused on a great variety of causes and interests, abound. They create a bewildering maze, but they also provide a means of socialization and constructive activity. Along with increasing urbanization we see a rather unrealistic romanticization of rural living and an enormous nostalgia for the rural environment.

\section{Communication}

The media have enlarged greatly the vision of "the good life" and, because of their persuasive power; have added an increasing burden on the human capacity to distinguish propaganda from facts. Their influence is global, ranging from economics to politics to "heroes" to music to modes of dress. The control of content and style seems to be narrowly constructed. The viewing-listening-reading audience, for example, receives the same selection of national and international news in the same style, though there are some exceptions, of course. The pervasiveness and immediacy of modern communication can turn eccentricities into fads, incidents into movements. The notion of a"generation gap," for instance, has been accentuated by the pronounced attention it has received. That youth are affected in many ways by the media goes without saying. 


\section{VIEW OF MAN UNDERLYING THIS STATEMENT}

"Every man is in certain respects

a) like all other men,

b) like some other men,

c) like no other man." (3)

That is to say: All human beings have qualities in common that make them human. The biological endowments of human beings, the physical environment in which they live, and the societies and cultures in which they develop, have some common features. Members of subgroups have additional qualities in common. Similarities exist, for example, among people in a certain socio-cultural group, among professional groups, among people belonging to the same economic stratum. But no one person is exactly like another. Each individual inherits a unique combination of biological characteristics. His environment is made up of a unique combination of factors. From birth onward he is shaped by countless, successive actions between his developing self and his environment. A given sequence of critically determining situations is never duplicated. Hence every man is in certain respects like no other man. It is important that the marvel of infinite variation among human beings never be forgotten. No general view of man fits any single individual.

Man is a holistic being. One may emphasize the physical, mental, emotional, and spiritual components of his makeup, but these components are not discrete. The whole is the synthesis of the parts.

Man is a social being. He is a product of the interplay of the environment and the individual — not exclusively of one or the other. Neither is supreme. Gesell left too much up to a random "magical" unfolding, while Skinner goes too far in the other direction by assuming an empty box, the old idea of man born as a "tabula rasa". Healthy growth occurs through appropriate interaction between man and the environment.

Man has a range of choices, but his choices are not unlimited. Total free will is an impossibility. Particular people, by virtue of their membership in a given population group or subgroup, have a broader or narrower range of choices in specific domains. At different times they have different choices.

Man is a developmental being, moving toward self-realization. Every person wants to be significant. The developmental process is never-ending. In it we see the totality of human life. No developmental stage is static. Each stage is related to other stages and builds toward other stages. Each stage is seen as having its own significant aspect. Each is characterized by stresses and exhilarations. The degree of stress and exhilaration in adolescence is enormous because of the great number of new experiences encountered in adolescence. The attainment of sexual maturity and the upsurge of tremendous physical and intellectual capacity are examples. 
Man influences and is influenced by a variety of complex systems and subsystems. He acts and is acted upon. Throughout his life he has the capacity to grow, to change, to modify his behavior in accordance with his values. Value formation within the individual is a continuing process, partly emotional, partly intellectual. It is born out of interaction between the individual and the systems that touch him.

\section{VIEW OF ADOLESCENCE UNDERLYING THIS STATEMENT}

The concept of adolescence emerges as part of the view of man. Historically it is a comparatively new concept. Our own view of adolescence, while it embodies some features of those theories, comprehends our experience in working with youth and our reflective thinking upon those experiences.

Once more we emphasize that we do not see adolescence purely as preparation for adulthood. Rather we see it as one part of the total developmental process-a period of tremendous significance distinguished by specific characteristics. Basic to our view is the concept that adolescents are growing, developing persons in a particular age group - not pre-adults, pre-parents, or pre-workers, but human beings participating in the activities of the world around them. In brief, we see adolescence not only as a passage to somewhere but also as an important stage in itself.

In setting down what we consider to be the significant characteristics or key concepts of adolescence, we call attention again to the fact that they will not apply in total to any person, group, or subgroup. Circumstances and timing, combined with individual differences, make for an infinite variety of behavior patterns, interactions, and outcomes.

\section{Key Concepts of Adolescence}

Experience of physical sexual maturity. A phenomenon particular to adolescence that never occurs again in the life of the individual is the process of developing sexual maturation, different from the state of accomplished sexual maturation. Biologically this is a totally new experience. Its significance is due partly to its pervasiveness and partly to the societal expectations surrounding it. It creates in adolescents a great wonderment about themselves and the feeling of having something in common with all human beings. It influences their whole relationship to each other, whether male or female. Entering this part of maturity also stimulates them to newly assess the world. Indicative of the importance attached universally to maturation of the sex organs are the puberty rites and initiation rituals that mark the transition from childhood to adulthood in many cultures, including present day USA.

Experience of withdrawal of and from adult benevolent protection. Along with biological maturity attained in adolescence come varying degrees of withdrawal of and from the protection generally given to dependent children by parents or substitutes. We know that some young people were never protected, even as children, but we assume a modicum of protection as a healthy base. Whatever the degree of previous protection, the adolescent is moving out from the family toward interdepen- 
dence (not independence, but interdependence) in three areas: (1) with his peers, his own generation; (2) with his elders, but now on an interacting or a rebellious level instead of a dependent level (adults often increase their attempt to control and direct adolescents, which tends to promote active rebellion); and (3) with younger children, not on a play level but on a beginning-to-care-for-and nurture level. This process of moving away from dependency creates tension and emotional conflicts.

Consciousness of self in interaction. The development of self and the searching for self starts in childhood, but the intellectual as well as the emotional consciousness of self in interaction with others is particularly characteristic of adolescence. It is a time when personal meaning is given to new social experiences. The young person defines for himself what he is experiencing in his relationships with others. His "meaning" may be different from that of those with whom he is interacting, but so long as it makes sense to him he can grow and move forward. The kind of categories he used as a child to figure out the world begin to break down. What may have been clear and explicable may suddenly become inexplicable.

Re-evaluation of values. Though the formation of values is a lifelong developmental process, it peaks in adolescence. It is related to both thinking and feeling, and is influenced by human interaction. In our culture where young people are likely to be exposed to a variety of contradictory values, questioning begins even in childhood. The adolescent engages in re-evaluation of values that have been either accepted at an earlier age or simply rejected because of individual resistance. He moves beyond simple perception (if I burn my hand it hurts) and sees things in a moral framework as "good" and "bad." He is consciously searching for value clarification. He becomes a moral philosopher concerned with "shoulds" and "oughts." Given the inconsistency of a society whose institutions frequently do not follow the general intent of the ideological system, value confrontations are inevitable. The young, because of the intensity of their total being, tend to be uncompromising. They may opt clearly for a thoroughly egalitarian value system, or they may give up and become cynics. The wish of each generation to start over again is not new. What is new in our time, however, is the intensity and the worldwide drive to translate this wish into reality.

Again, the younger child is constantly developing mastery of the outer world, but the adolescent encounters his untold with a new intellectual and emotional consciousness. He meets his world less as an observer and more as a participator who actually has a place to fill.

Experimentation. The young are possessed of greater physical, mental, and emotional capacity and therefore of a great thirst to try out those capacities. Experimentation is writ large-as important as eating or sleeping. Human beings learn through experimentation from childhood on. The child explores, for instance, by touching, putting things into his mouth, etc. Adolescents need to experiment with wider circles of life-meet various kinds of people, see other cultures. They need to experiment with their own strength and value systems-lead a group, try out inti- 
mate relationships, engage in some form of adventure. The experimentation necessary to adolescents usually includes a feeling of risk. It is their way of learning about their own and the surrounding reality.

This need is fraught with danger because adolescents are not as cautious as adults, yet it must have some outlet. It can become a major form of positive healthy development of the young.

\section{Qualities of Adolescence}

Linked inseparably with the major phenomena of adolescence outlined above are a number of qualities or characteristics peculiar to this period; at least they are present in heightened form. We look on them as healthy and normal, not as detrimental or negative. A few of the more significant ones are highlighted here.

The drive to experiment is coupled with a mixture of audacity and insecurity. The audacity is related to not being experienced enough to envision the harmful consequences of a given action; the insecurity is related to the uncertainty that accompanies inexperience and the lessening or withdrawal of protection.

A deep sense of loneliness and a high degree of psychological vulnerability are two other specific qualities of adolescence. Every attempt at experimentation and reaching out is new and very intense. If the outcome is negative it is exceedingly painful because youth do not have a "bank" of positive experiences to draw from when defeats occur. Adults can say,"Oh well, you'll get over it," but such remarks annoy more than they comfort.

Enormous mood swings are usually cited as characteristic of adolescence. Many factors contribute to the swings. Physiological changes are related to emotional changes. Moving from dependence to interdependence creates a whole series of tensions and conflicts. The impact of peers is magnified. Ambivalence is common. The yearning to jump into the next stage of development co-exists with the desire to have things stay as they are. The feeling of omnipotence tangoes with the feeling of helplessness and inadequacy. The cocksure conviction that "it won't happen to me" plays hide and seek with the fear that it will. Being expected to act like an adult one minute and being treated like a child the next is experienced as confusing. How can one be too young to do almost everything one wants to do, and adult enough to behave as "they" think one should? Seeing parents as mere humans with frailties can be terrifying after having depended on them as all-wise.

Adolescents have a strong peer group need. They stress cooperation with that segment of the group with which they identify. The sub-groups they form are often very tightly knit. To gain group acceptance the individual seems to relegate his personal competitive drives to second place, at least temporarily. The emphasis is on cooperation, whether the goal is positive or negative-manning a hotline emergency service, for example, or "ripping off" a certain store.

Finally, adolescents need to be argumentative and emotional since they are in the 
process of trying out their own changing values and their own relationships with the outer world.

Summarizing the attributes of adolescence into one concept is difficult and may be an oversimplification. Erik Erikson gave us the concept of the age of identityseeking; therefore his stress on provision of a moratorium as condition for healthy development.

I (Konopka) prefer to think of adolescence as the AGE OF COMMITMENT. It is the move into the true interdependence of men. The struggle between dependency and independence - so often described in the literature-is an expression of this entrance into interdependence.

Commitment includes the search for oneself, as Erikson stressed, but it also points toward the emotional, intellectual, and sometimes physical reach for other people as well as ideas, ideologies, causes, work choices.

This move toward commitment is so serious and so significant that providing healthy conditions to let it unfold becomes just as crucial for human development as providing healthy conditions for growth in early childhood. It elevates adolescence from a stage frequently regarded as one that must be endured and passed through as rapidly as possible to a stage of earnest and significant human development.

\section{Conditions for Healthy Development of Youth}

Looking back now on our view of man and adolescence in the cultural context of the United States in the 1970's, we begin to see clusters or constellations of associated imperatives, skills, and tasks that-taken together-create a climate conducive to healthy development of youth.

A pluralistic society with egalitarianism as an ideal demands participation of people. Therefore it is quite clear that creation of conditions that facilitate healthy adolescent development begins with the encouragement of equal and responsible participation by youth in the family or other societal units.

Because we are living in a complex society, choice-making becomes increasingly important. It cannot be based on instinct. Therefore youth must develop the capacity to make decisions in many areas: school interests, work interests, use of discretionary time, the kind of friends they want to cultivate, and so on. Practical learning opportunities are essential.

As the protections normally associated with childhood are withdrawn and adolescents move toward wider interdependence, particularly with their peers, they need to have a sense of belonging to their own age groups and to adults as well. They need to find ways to interact with peers - both male and female. They need to acquire the skills to handle their sex drives, to develop and maintain friendship, to experience intimacy. They may choose to join a youth organization or a gang, take 
up a "cause," concentrate on dancing or listening to records in a group, or adopt some other activity — and they should have the opportunity to do so.

Because of the conflicting values adolescents encounter in a rapidly changing world, they should have the opportunity to thrash out their reactions, consider the pluses and minuses, and try to determine where they themselves stand so that they will be better able to deal with ideas of all shades-including demagoguery. Those working and living with youth can foster healthy value formation by encouraging open discussion and refraining from trying to superimpose their values upon them.

Although "Who am I?" is a question that recurs throughout life, the search for identity becomes more conscious and highly emotional during adolescence. Therefore the young need a chance to reflect on self in relation to others (some use their peers as mirrors) and to test self in a variety of settings. The process is a healthy one so long as it does not consist entirely of looking inward.

In recent years people in the helping professions, and laymen as well, seem to have become engrossed in a very individualistic approach to healthy psychological development. Value clarification is discussed in terms of one person examining his own values; participants in therapy groups delve endlessly into themselves; books on self-analysis keep rolling off the presses. While we believe it is a condition of growth to be able to discover who one is, we also believe that inordinate preoccupation with self in the search for identity can become very unhealthy. Hence we emphasize the importance of looking outward as well as inward.

Since experimentation is essential to learning, adolescents should have the opportunity to discover their own strengths and weaknesses in a host of different situations, to experience success and also learn how to cope with adversity and defeat. These skills are usually acquired through active participation. Therefore adolescents should have a genuine chance to participate as citizens, as members of a household, as workers - in general, as responsible members of society.

Experimentation involves risks. With audacious but inexperienced youth doing the experimenting, the risks are magnified. If experimentation is essential to learning, as we have said, then it can be argued that adolescence should be a period in which youth can experiment without suffering disastrous consequences when they fail or make mistakes; in other words, that the means for a psychosocial moratorium should be provided. It can also be argued that learning and growth will not occur unless youth are held responsible for their actions and that participatory activity without such responsibility becomes tokenism.

Our view is that some allowance for experimentation is important for healthy development, but that the "moratorium" should not be total. Adolescents should be allowed to experiment with their own identity, with relationships to other people, and with ideas, without having to commit themselves irrevocably. They should be able to try out various roles without being obligated to pursue a given course-in school or in the world of work, for example. They should also have the opportunity to practice with limited hurt if they fail, because while their inexperience does not make them 
inferior to adults, it does make them different. On the other hand, youth should understand that genuine participation and genuine responsibility go hand in hand; that a basic tenet of our social system is: for every right or set of rights there is a corresponding responsibility or set of responsibilities. To illustrate: young or old, a bona fide voting member of a governing board or some other decision-making body is responsible for his vote. Also we believe that youth should be helped to develop a feeling of accountability for the impact they have on other human beings-accountability not in a hierarchic sense, but in the context of a relationship among equals.

Finally, a climate that facilitates healthy development should provide opportunities to cultivate the capacity to enjoy life, to be creative, to be frivolous, to do things on one's own, and to learn to interact with all kinds of people-people of different races, different interests, different life styles, different economic and cultural backgrounds, and different ages.

To recapitulate, conditions for healthy development should provide young people with opportunities:

- to participate as citizens, as members of a household, as workers, as responsible members of society;

- to gain experience in decision making; to interact with peers and acquire a sense of belonging;

- to reflect on self in relation to others and to discover self by looking outward as well as inward;

- to discuss conflicting values and formulate their own value system;

- to experiment with their own identity, with relationships to other people, with ideas; to try out various roles without having to commit themselves irrevocably;

- to develop a feeling of accountability in the context of a relationship among equals;

- to cultivate a capacity to enjoy life.

Given these conditions, adolescents will be enabled to gain experience in forming relationships and making meaningful commitments. They are not expected by the adult world to make final lifelong commitments; the expectation is related to their own need for interdependence and humanity's need for their commitment to others without losing themselves.

\section{OBSTACLES TO PROGRESS OF NORMAL DEVELOPMENT}

Having looked at some of the conditions that facilitate healthy development, 
we now look at the other side of the coin: obstacles to the progress of normal development. Both the presence of unfavorable factors and the absence of favorable factors constitute obstacles.

The factors selected for discussion here are closely related to the key concepts and qualities of adolescence described earlier. Those that impede normal development of all human beings - such as lack of nutrition, inadequate housing, poverty in general, racial discrimination - are exceedingly important and are acknowledged here as basic. In addition, we wish to underline the following specific obstacles to healthy development of adolescent youth.

\section{Violation of Adolescents' Self-Respect by Adult World}

Violation of self-respect is detrimental to all human beings. In adolescence, because of increasing self-consciousness and interdependence with peers, anything that violates self-respect—such as racial discrimination, or being disregarded as a significant human being, or being labeled a failure-is taken with special hurt. It may result in withdrawal, complete destruction of self, mental illness, drug abuse, or enormous hostility. The adolescent sees many inconsistencies in the adult world which were less definable in childhood. He often perceives simple criticism as a demeaning"put-down." To ignore or to laugh off his hurt and frustration is to violate his self-respect in a very real way.

\section{Society's View of Adolescence as Preparatory}

The prevailing cultural view that adolescence is only a time of preparation for adulthood is harmful because it places youth in an ambivalent situation where they are neither children nor adults. It causes expectations to be extremely confused: in one instance "You're too old to behave like that;" in another"You're still a child you know."The very rhetoric that adolescence is transition may be an obstacle in itself.

\section{Prolonged Economic Dependence of Youth}

Youth's bursting energy, thirst for adventure and yearning for a productive role in society make it difficult for some to accept prolonged economic dependence. School dropouts especially in the middle class economic bracket often are motivated by wanting to make it on their own. A sense of violation of self-respect, inflicted by school or community, contributes to dropouts at all economic levels, perhaps more so at the lower level. While modern technology has increased the need for the more extensive knowledge and training that long schooling makes possible, educational requirements for many jobs are "standard" rather than job-related. They should be less rigid.

\section{Limited Outlet for Experimentation by Youth}

Urbanization and population density diminish possibilities for experimentation. Though mobility increases at adolescence, space and places to go are lim- 
ited. Opportunities for part-time work experience are limited by the inability or unwillingness of business and industry to accept large numbers of young people into their operations and by the desire of labor organizations to lock up jobs and entrance to jobs.

Mistrust is another basis for many restrictions on experimentation. Some restrictions are warranted on the grounds of reasonable protection, but others-such as some youth-serving organizations now allowing 16- and 17-year-olds to go on hikes without an adult present-are exaggerated.

\section{Popular Acceptance of the Generation Gap Concept}

In recent years the concept of a generation gap has been widely accepted as inevitable - a notion reinforced by the media. Worse, the so-called gap has been acted out as hostility by both adults and young people, each placing the other in the role of adversary. This state of affairs is an obstacle to the healthy development of adults as well as youth since they are interdependent.

\section{Influences that Encourage Adolescent Egocentricity}

An outcome of increased personal alienation and separation from responsibilities and participation has laden the problem of adolescent egocentricity. The lack of effective interpersonal competencies, both within the teenage generation and across teenage and adult generations, escalates the tendency toward a narrow individualism. The relativism inherent in the fad to "do your own thing"too often leads to further withdrawal and separation. Such experience can act as an effective negative barrier by preventing the development of needed interpersonal competency.

\section{Lack of Opportunity for Moral Development}

It is important to note that many adolescents stabilize their value system at levels well below universal values of social justice. Society's failure to provide for significant experience and careful examination/reflection of that experience for most teenagers literally stunts their moral development. Simple precepts are no more acceptable. Critical to our statement is the finding that there is almost no increase in the level of moral maturity beyond that reached during adolescence. Clearly according to Kohlberg ${ }^{(4)}$ and Konopka ${ }^{(5)}$ the time to stimulate maximal psychological and moral maturity is during this stage.

\section{Society's Confusion about Sex}

A conspiracy of silence shout sex or banal exchange on the level of advertising clichés are still characteristic of the wider society. Such practice prevents young people from clarifying their own attitudes about one of the most forceful drives at this age. It pushes them into clandestine experimentations that often frighten or demean them. Such ignorance has helped to increase the incidence of venereal disease in young people. 


\section{Society's Belief that Family is the Only Place for Youth}

For certain young people the fact that the traditional family (father, mother, children) is considered the only unit conducive to healthy growth, with no alternatives, is damaging. With no legitimate substitute available they are forced into runaway episodes, hiding, drugs.

\section{Dominance of Youth Organizations by Adults}

Organizations are instruments of our society. Causes are fought and won by organizations. Yet when the young organize they are seldom permitted to run their own show. Adult needs often supersede the healthy development of youth. Adult leaders of youth organizations tend to view teenagers as minds to be molded and shaped as if they were young children. Governing boards are dominated by adults who make policy, "know what is best." Adult" advisers" engineer subtle (and sometimes not so subtle) roadblocks to action. Formal organizations which presumably exist to serve youth become top heavy bureaucracies impervious to the suggestions youth offer. Such tactics prevent youth from gaining experience as genuinely functioning citizens and breed cynicism.

\section{Denial of Equal Participation to Youth}

In almost every aspect of society—family, school, civic organizations, political groups, social and religious groups-youth are usually not permitted equal participation. They may not even be allowed free passage into the organizations. This denial is inconsistent with the notion that people learn and develop by doing.

\section{Uneven Laws Pertaining to Youth}

Laws pertaining to youth vary from state to state. Some are outmoded; some are ambiguous; all are variably administered. For those youngsters who run into legal difficulties the obstacles to healthy development are multiplied tenfold. If the offenders are institutionalized they are cut off from normal interaction with their associates and their development is stunted — contrary to the philosophy of the juvenile court which was established so that young persons could be protected and rehabilitated instead of being punished. "Juvenile status offenses" (truancy, chronic absenting, and incorrigibility for example) are offenses only if committed by the young. Teenagers are punished for behavior often necessary at that age. Laws making it impossible for young people to get medical care without parental consent are obstacles to physical health and to mental and emotional health as well.

\section{RECOMMENDATIONS}

Several considerations influenced our approach to recommendations concerning the kind of programs and research endeavors we believe would facilitate the healthy development of adolescent youth. 
The fact that this statement is addressed to a governmental agency led us to direct our suggestions primarily toward action that could be instituted by government.

We do not adhere to the simplistic view that by government action alone or by individual action alone will healthy development of youth be assured. At best it can only be facilitated and that pursuit will require the best efforts of both worlds-public and private.

It is understood that the fulfillment of basic needs is the foundation on which facilitation of any kind of human development rests. This statement is concerned for the most part with the psychosocial aspects of healthy development. Our recommendations are directly related to our previously stated view of adolescence taken as a whole.

Two approaches to recommendations were considered: (1) giving attention individually to each system in which adolescents live and move-educational, family, work, discretionary time, correctional, and governmental; (2) looking at the total picture and thinking in terms of remedial or rectifying programs and research efforts. The second approach was agreed upon, chiefly because each system is so closely related to other systems that any program, to be effective, necessarily would have to involve more than one system. The pivotal position of the educational system should be specially noted. In the life of adolescent youth the schools are of critical importance. Unless they are supportive of programs aimed at reform in other areas, those programs are likely to fall short.

We begin with some general observations that apply to all systems.

\section{Priority Concerns Related to All Systems Serving Youth}

We assign top priority to actuating a major effort to educate adults who work with youth about conditions that facilitate health, development, and how such conditions can be created. Envisioned is an interdisciplinary focus on youth in formal and informal educational programs designed to improve the skills, insight, and understanding of persons involved with youth-teachers, parents, counselors, social workers, recreation directors, correction officers, health professionals, and other youth-serving personnel.

We also urge greater emphasis on the education of youth (1) to improve their competency and self-confidence in using the resources and power to which they have access and (2) to develop in each individual the strength or courage to cope with the system as it affects him.

Changes in structure and program are recommended whenever required to facilitate significant input by youth. Experience with federal programs, such as Models Cities, Housing, and Community Action could provide direction. In the educational system, for example, consideration might be given to student membership on the school board or key committees, or the development by students of student rights 
statements, or the legitimization of organizations run by youth for youth. This is not, however, to suggest the development of a professional group of adolescents who are presumed to speak for the adolescent community. Adolescents, like any other population group, are not all of one mind.

\section{Criteria for Programs and Systems Serving Youth}

The effectiveness of programs and systems serving youth can be judged by the opportunities they offer youth and the credibility they enjoy. We believe those which merit support are distinguished by:

- Provision of opportunity for youth to have experience in (1) making choices; (2) making commitments; (3) experimenting with a variety of roles to"try out" the choices and commitments they make.

- Credibility: validity of the program in the eyes of those served.

Unless real options are available, choice-making becomes an empty phrase. Pseudo decision-making does not promote developing commitment. Therefore, intervention logically should be focused on the removal of limiting factors.

Carrying this line of reasoning further, law should be used to support healthy development rather than as it is now, presumably to, curb socially disapproved behavior (often including behavior that actually has become more common.) ${ }^{(6)}$ The formulation and use of policy should be guided by the same principle.

\section{Greatest Urgency}

It can always be said (and all too often is) that progress on this or that front cannot be made until such and such changes are made on some other front. While we are well aware of the complex interrelationships that make remedial action difficult, we believe an intensive national effort must be made to rectify conditions in areas where youth are being most cruelly battered and mangled.

1. We have singled out the correctional system as the greatest offender because it is the one in which youth are most powerless once they enter it. A total and concerted effort should be made to:

a) Close mass juvenile institutions;

b) Develop substitute living situations for young people who cannot live at home;

c) Provide access of juveniles to legal aid.

2. We suggest support of programs to make education (formal and infor- 
mal) a base for healthy growth instead of humiliation and frustration. We recommend:

a) Creation of options and alternatives within and outside of existing school systems. The deliberate promotion of pluralistic learning environments staffed by adults from a variety of backgrounds would provide for greater learning experience and participation by a larger segment of teenagers. These options would include the development of adolescents as teachers and counselors—staff participants-in schools. Prior inservice (or other) education of participating teachers would be essential.

b) Provision of experiential education for young people through community participation.

c) With priority given to programs which educate teachers and other youth workers to genuinely respect and work effectively with adolescents from various backgrounds.

d) Our final suggestion is the creation of significant employment opportunities for youth. Our concern here is for underemployed and unemployed youth in need of meaningful job opportunities as well as educational and vocational counseling.

3. We have refrained from making detailed proposals for programs because that must be done by the people who will carry them out.

We suggest that the Office of Child Development convene a small conference to develop priorities and exchange ideas for additional projects.

\section{Research and Data Gathering}

Support should be given to research focused on barriers to opportunities for choice-making, experiencing commitments, and experimenting with many different social roles; that is, barriers to accomplishing that which we said all program changes should be designed to accomplish. We also believe:

- The combined efforts of youth and adults should be employed in research.

- Youth-initiated projects should receive serious consideration and youth should be encouraged to come forward with ideas for investigation.

- In projects undertaken, youth should provide documentation and monitor all processes, rules, norms, and points of contact with youth organizations.

- Particular attention should be given to field research studies instead of basic laboratory research; that is to examination of programs in natural environments. 
- Data on youth should be feathered uniformly throughout the United States and reported periodically for each state. Findings should be analyzed and implications for national trends primed out.

- It is noted that at present no major office of the federal government carries a title with specific reference to adolescence or youth. It is highly recommended that such a reference be carried in the title of a governmental office responsible for coordinating, and facilitating research and experimental programs concerned with youth development.

- The Children's Bureau by tradition has carried this responsibility, but its major focus has been on the development of the young child. It has done superbly in improving health and emotional conditions for small children.

Yet too little attention in either research or experimental efforts has been given to youth. Youth in poverty (often of minority status) suffer not only from childhood deficiencies but carry the additional burden of adult hostility directed toward them. Furthermore all their adolescent needs are thwarted in the extreme: no hope for social or geographic mobility, no opportunity for legitimate adventure, no possibility for accepted social involvement. Middle class youth also often feel so alienated that their hostility mounts and is vented on other groups of youth the adult world or things.

As a country, we know little in hard facts of the aspirations, hopes, and wishes of all our youth. The experience of other countries has shown that an office for youth affairs in the central government can perform a valuable function without becoming dictatorial. Use of the term "adolescence" or "youth" in the title of the office would call attention to the importance of promoting the healthy development of persons in that age group. (The Center for Youth Development and Research at the University of Minnesota may present a working model for such a governmental organization.)

\section{EPILOGUE}

"How can I establish a figure, even the crudest outline, if I don't know what I'm doing?... What do I know of the causes? The vital structure of a man that lies beneath the surface and that my eye can't see? How can I know what creates from within, the shapes I see from without?"(7)

Those are always the questions artists, scientists, educators, and finally all people must ask. They ask them all their lives, but especially in adolescence. The preceding statement raises the questions of deeper understanding of one age group related to our present day culture. It is set within the value system of a democratic society with all its possible advantages and its desperate search for realization.

It is my conviction that each life period has its sorrows and exhilarations for the individual who experiences them as well as for those surrounding him and that each period has its significance for the continuous development of the human race. Youth is neither golden nor rotten. It has the potential of all human ex- 
perience. Only the adult generation is still partially responsible for helping youth to be healthy, sturdy, and able to cope with its own problems and also with the problems of the total society. And all human beings have a responsibility neither to demean others nor to hinder others from developing. Observation alone is never sufficient. It leaves the door open to negative forces sweeping over us. We must take the initiative first, to eliminate the destructive forces impinging on our youth and second, to strengthen those forces that will enhance their health and thus the fate of all of us. The world may never be perfect, but much can be done!

\section{Notes}

(1) Muuss, R.E. (1962). Theories of adolescence (2nd ed., p. 4). New York: Random House.

(2) Kristol, I., (Feb. 1973). Job satisfaction: Daydream of alienation? AFL-CIO Federationist.

(3) Kluckhohn C., \& Murray, H.A. (1949). Personality in nature, society, and culture (p. 35). New York: Alfred A. Knopf, Inc.

(4) Kohlberg, L., \& Kramer, R. (1969). Continuities and discontinuities in childhood and adult moral development. Human Development, 12, 93-120.

(5) Konopka, G. (1973). Formation of values in the developing person. American Journal of Orthopsychoiatry, 13(1).

(6) The population of delinquency institutions for girls consist in the majority of girls whose "crime" is involvement in sexual experimentation.

(7) Stone, I. (1959). The passionate journey (p. 187). New York: Doubleday and Co.

\section{Selected Bibliography Adolescence}

Alissi, A.S. (1972). Concepts of adolescence. Adolescence, 7(28), 491-510.

Bubler, C. (1935). From birth to maturity. London: Kegan Paul, Trench, Trubner \& Co, Ltd.

Coleman, J.S. (1961). The adolescent society. NewYork: The Free Press.

Konopka, G. (1966). The adolescent girl in conflict. Englewood Cliffs, NJ: PrenticeHall, Inc. 
Konopka, G. (1971). Adolescence in the 1970s. Child Welfare, 50(10), 553-559.

Konopka, G. (1973). Formation of values in the developing person. American Journal of Orthopsychiatry, 43(1), 86-96.

Muus, R. E. (Ed.), (1962). Theories of adolescence (2nd ed.). New York: Random House.

Muus, R. E. (Ed.), 1971). Adolescent behavior and Society: A book of readings. New York: Random House.

\section{Man}

Dewey, J. \& Tufts, J.H. (1932). Ethics. New York: Henry Holt and Co.

Ellwood, C.A. (1938). A history of social philosophy. New York: Prentice-Hall.

Kluckholn, C., \& Murry, H.A. (1961). Personality in nature, society, and culture (2nd ed.). New York: Alfred Knopf.

Konopka, G. (1963). Social group work: A helping process. Englewood Cliffs, NJ: Prentice-Hall, Inc.

Nelson, L. (1956). Systems of ethics. New Haven: Yale University Press.

Smuts, J.C. (1926). Holism and evolution. London: Macmillan and Co., Ltd.

Stern, W. (1938). General psychology from the personalistic standpoint. New York: The Macmillan Co.

\section{Culture}

Adamic, 1. (1945). A nation of nations. New York: Harper and Brothers Publishers.

Hoebel, E., A. 91972). Anthropology: The study of man (4th ed.). New York: McGrawHill Book Co.

Maritain, J. (1958). Reflections on america. New York: Charles Scribners's Sons. 